\title{
Racial Differences and Pedestrian Safety: \\ Some Evidence from Maryland and Implications for Policy
}

\author{
Randal Reed and Siddhartha Sen \\ Morgan State University
}

\begin{abstract}
In the 1990s, federal legislation was passed requiring transportation planning to incorporate the interests of all stakeholder groups. One urban transportation mode that is often ignored is pedestrian movement. A group particularly susceptible to difficulties in this mode is the elderly. This study surveys the attitudes of senior citizens in regard to pedestrian safety and motorist interactions. We examine the attitudes of elderly pedestrians concerning many aspects of pedestrian travel. The study finds that this group often views itself as disenfranchised. This study provides insight into what areas of pedestrian activity the elderly find troublesome and looks at the differences between urban and rural attitudes in regard to this issue.

The results show that African Americans and Asians have a much higher rate of positive (safety conscious) responses to the questions in the survey. This indicates that they believe that they are more aware of pedestrian safety and that they comply with laws regarding pedestrian safety at a higher rate than their Caucasian counterparts. In addition, gender and geographical location seem to impact the responses. Urban seniors have a much higher positive response rate than suburban and ex-urban seniors.
\end{abstract}


A comparison with previous work finds that these attitudes expressed in the survey are at odds with the known demographic data concerning who is at higher risk to be involved in a pedestrian accident. The increased awareness on the part of urban respondents is compatible with the more pedestrian-friendly environment of urban areas, but the racial difference in responses is not compatible with the accident data.

\section{Introduction}

It is important to analyze the attitudes and needs of senior citizens on pedestrian safety since not much has been written on the topic. This is despite the fact that the elderly are more vulnerable to fatal accidents (Winter 1984; Harrell 1996; Carmeli et al. 2000). In particular, there is a lack of literature that examines the racial differences in attitudes toward safety. This is paradoxical since minorities are at a greater risk of pedestrian accidents (Campos-Outcalt et al. 2003; Surface Transportation Policy Project [STPP] 2002). The changing nature of national transportation policy since the early 1990 s creates an emphasis on concerns for the elderly, especially their safety. This changing focus also creates an emphasis on sustainable development and livable cities. The concepts of sustainable development ${ }^{1}$ and livable cities are synonymous, and such cities should include compact urban form, reduced automobile use, and creation of livable and community-oriented human environments (Wheeler 2000; Frey 1999; Duany et al. 2000). ${ }^{2}$ Clearly, a community-oriented environment would take into account the attitudes and needs of seniors concerning their safety and perceived pedestrian problems.

Given this situation, the article examines the attitudes of senior citizens in Maryland toward pedestrian safety and pedestrian safety campaigns. We examine the differences in attitudes by geographic dispersion (urban vs. rural), gender, and race. We first present a brief overview of the changing nature of the national transportation policy and its implications for the elderly and sustainable cities. This is followed by a review of the literature of pedestrian safety especially as it relates to seniors and various racial groups and effectiveness of campaigns. We then present the data and methodology. This is followed by the results of a survey of more than 800 seniors in the central Maryland region concerning pedestrian safety and attitudes. The next section contains the results of six focus groups that were conducted to hear the opinions of the elderly on transportation and pedestrian safety and maneuverability. The final section contains some concluding remarks, implications for policy, and recommendations. 


\section{Changing Nature of U.S. Transportation Policy and Its Implications}

For most of the past century, national transportation policy focused on accommodating the demand for travel and the needs of automobiles through the construction of roads and other transportation facilities (Horan and Jordan 1998). Soon after World War II, the United States embarked on construction of a 44,000-mile nationwide system of highways with the passage of the Federal Highway Act of 1956 and the implementation of the Interstate and Defense Highways program. Construction of highways became one of the largest civil engineering feats of the century, but also tore apart the existing urban fabric of the United States (Kay 1997).

Interest in such issues as the travel needs of the elderly has recently taken hold among transportation planners and policy-makers as they address such issues as environmental justice, integration of bicycling and walking into transportation systems, disability, and the Personal Responsibility and Work Opportunity Act of 1996 (welfare to work). ${ }^{3}$ Public participation and equity is also central to accomplishing the vision of the Transportation Equity Act of the 21st Century (TEA-21) of 1998, which builds on the Intermodal Transportation Equity Act of 1991 (ISTEA). ${ }^{4}$

Passage of ISTEA by the Congress in 1991 fundamentally altered U.S. transportation policy. As pointed out by Horan and Jordan (1998), ISTEA created an urban transportation planning process that linked it to several policy domains-environmental, economic, and social. The goal was to improve the overall quality of life in communities. Its policy emphasis included improved mobility for the elderly, disabled, and economically disadvantaged. As discussed, this changing focus also creates an emphasis on sustainable development and livable cities that include compact urban form, reduced automobile use, and livable and community-oriented human environments. Certainly, ensuring a safe pedestrian environment for the elderly is a step toward promoting such cities.

Concerns for the elderly, especially their safety, are also central to accomplishing the vision of TEA-21 of 1998, which builds on ISTEA (Passwell 2001). In addition, USDOT adopted strategic goals that emphasize nondiscrimination in implementation of programs, policies, and activities (http://stratplan.dot.gov/archive). The "Human and Natural Environment Strategic Goal," outlined in USDOT's "Strategic Plan" (http://stratplan.dot.gov/archive), calls for the protection and enhancement of communities and natural environments affected by transportation. 
The evolution of transportation policy includes a concern for the environmental justice issues of equity and the evaluation of impacts on various demographic groups. The origins of government's attempts to address the environmental justice issue date back to February 11, 1994, when President Clinton signed Executive Order (E.O.) 12898, Federal Actions to Address Environmental Justice in Minority Populations and Low-Income Populations. In response to presidential directives concerning E.O. 12898, USDOT issued a proposed Environmental Justice Strategy on February 13, 1995, and then a final order on the subject, Order No. 5610.2 (Order to Address Environmental Justice in Minority Populations and Low-Income Populations), on April 15, 1997. The Federal Highway Administration (FHWA) issued DOT Order No. 6640.23, FHWA Actions to Address Environmental Justice in Minority Populations and Low Income Populations, on December 2, 1998. The order requires the FHWA to implement the principles of the DOT Order 5610.2 and E.O. 12898 by incorporating environmental justice principles in all FHWA programs, policies, and activities (Forkenbrock and Schweitzer 1999).

One of the common modes of urban transportation is by foot-pedestrian. While transportation infrastructure tends to concentrate on public transit and highway and road systems, pedestrian needs are supposed to be considered as important when devising these systems. One group of citizens who tend to use public transportation and pedestrian infrastructures to move about are the elderly. This age group tends to suffer from medical conditions that require extra care, time, or infrastructure to safely maneuver in or near traffic. ISTEA and TEA-21 require jurisdictions to consider the needs of this constituency when planning transportation systems.

The results of this article provide an interesting insight into the opinions of this large stakeholder group's feelings toward pedestrian transportation problems and the safety of walking in the presence of automobile traffic. The results point to differences in these feelings that are a function of gender, race, and, in some instances, geographical location. Understanding these differences is critical to the implementation of a public transportation infrastructure that incorporates pedestrian traffic.

\section{Review of the Literature}

Previous work in this area is sparse and focuses primarily on safety initiatives that involve infrastructure, driving patterns, and jaywalking tendencies. Of course, 
there are a few exceptions. Harrell (1996), for example, examines the perception of the elderly on traffic risks especially in signal-controlled crossings in the Canadian context. Impact of variables such as gender, traffic and pedestrian volume, and demographic characteristics on perceptions are an integral part of the study.

However, there is an abundance of literature on peripheral subjects. These include pedestrian walkways and habits (Hess et al. 1999); relationships between pedestrian accident locations on state owned facilities such as highways and urban arterials and the presence of riders loading and alighting from bus transit (Hess et al. 2004); effect of travel speeds and locations on pedestrian accidents (Gårder 2004); leader-follower behavior as it applies to jaywalking (Russell et al. 2001); safety of elderly pedestrians during street crossing (Carmeli 2002); sociodemographic and health characteristics and problems of older pedestrians (Langlois et al. 1997); safety and security of elderly and disabled travelers through the application of Intelligent Transportation Systems (ITS) (Mitchell and Suen 1998); difference in accident and fatality rates by race and gender (STPP 2002; Campos-Outcalt et al. 2003); and benefits of educational campaigns on pedestrian safety (Tyrrell et al. 2004; Mendelsohn 1973).

Despite their peripheral treatment, some of these studies have significance for this article. For example, Hess et al. (1999) found that pedestrian walkways in urban areas are much more pedestrian friendly than those in suburban areas. Safe pedestrian activity in suburban areas requires the pedestrian to detour much more often and for longer lengths than in urban areas. This increases the incentive to jaywalk and engage in other unsafe practices. We find similar findings in both the survey responses and the focus group discussions. Langlois et al. (1997) and Carmeli (2002) discuss the need for consideration of the special needs of elderly pedestrians such as increased crossing times and reduced traffic speeds. Focus group discussions highlighted these concerns among the elderly in our sample as well.

Studies that show racial and gender differences in jaywalking tendencies, pedestrian accidents, and fatalities are also of importance to our study since we found that minorities who are at greater risk have a higher perception of their own safe behavior and follow safety laws more stringently. Russell et al. (2001), for example, examined leader-follower behavior as it applied to jaywalking. "Models" were used to determine if observing someone jaywalking encouraged others to follow suit. It was found that this was the case. While there were only small differences, the study did find that African Americans were more likely to follow a "model" and 
jaywalk than Caucasians ( $5 \%$ for women and $7 \%$ for men). Our survey responses do not follow this result in that African Americans claim a much higher adherence to pedestrian laws than Caucasians.

An STPP study (2002) contains data describing the high accident rate for minority pedestrians in California. This is a trend that is heuristically observed nationally. Racial and gender differences in fatality rates also were established by other studies. Campos-Outcalt et al. (2003) explored rates of pedestrian fatalities in Arizona and how rates and circumstances of pedestrian deaths differ by race/ethnicity, urban or rural residence, age, and gender. The study found that American Indians had rates of pedestrian deaths higher than those of non-Hispanic whites. American Indian pedestrian death rates and relative risks were higher in rural areas than in urban areas. Compared to non-Hispanic whites, urban Hispanic males, rural Hispanic females, and urban African American females had higher relative risks.

Articles that illustrate the benefits of campaigns are also of special relevance to our study. Tyrrell et al. (2004), for example, states that designing and implementing research-based public education campaigns aimed at reducing pedestrians' overestimates of their own nighttime visibility could increase pedestrian safety. An earlier study (Mendelsohn 1973) argues that social science research can make public campaigns more effective by determining appropriate targets, themes, appeals, and media vehicles. As suggested by the study, the major task facing the communicator is to recognize, understand, and attempt to overcome public apathy. Here, social science research can be useful in determining appropriate targets, themes, appeals, and media vehicles. Our findings point to some of these targets and themes as expressed by different demographic groups.

\section{Data and Methodology}

This article draws from a study that was conducted as part of a research project funded by the Maryland State Highway Administration (Reed and Sen 2004) and the National Transportation Center at Morgan State University. The research was aimed at evaluating a public service campaign, "Walk Smart," concerning pedestrian safety as well as finding attitudes of citizens in regards to pedestrian safety. The results from general attitudes and desires concerning future safety campaigns are presented, but the effectiveness of the campaign is not assessed in this article. For a full discussion of the campaign and attitudes concerning the campaign, see Reed and Sen (2004). 
There were 809 valid returned surveys in our sample. Eighteen surveys were completed by people accompanying a senior to the senior center (under the age of 50); and those under the age of 65 completed a total of 110 surveys. Thus, almost 90 percent of the surveys are from people over the age of 65 . The basic demographic description of the data is presented in Table 1. Most of the respondents (over 60\%) were from Baltimore City. This is partially a function of demographics (a large number of seniors live in Baltimore City) and partially a function of the cooperativeness of the senior center coordinators in the city. In addition, just over two-thirds of the surveys were completed by Caucasians and about 20 percent by African Americans.

Respondents were not selected randomly from the population of senior citizens in the region. Instead, they were contacted through senior citizen centers in the region. While it is impossible to say with certainty, the average respondent would

\section{Table 1. Demographic Summary of Survey Data}

\begin{tabular}{|c|c|}
\hline Number of Responses & 809 \\
\hline Median age & 75 \\
\hline \multicolumn{2}{|c|}{ Gender } \\
\hline female & $84.80 \mathrm{~N}$ \\
\hline Male & $1286 \%$ \\
\hline No answer & $2.35 \%$ \\
\hline \multicolumn{2}{|c|}{ Race } \\
\hline African American & $1780 \mathrm{x}$ \\
\hline Asian & $606 \%$ \\
\hline Caucasian & $6724 x$ \\
\hline Hispanic & $0.12 \%$ \\
\hline Other & $5.32 \%$ \\
\hline No aniwer & $36 \%$ \\
\hline \multicolumn{2}{|c|}{ County } \\
\hline Allegtamy & $878 \%$ \\
\hline Baltimoer & 18918 \\
\hline Baltimore City & $6218 \mathrm{x}$ \\
\hline Cecil & $3.46 \%$ \\
\hline Charles & $694 \%$ \\
\hline Fredrick & $1.73 \%$ \\
\hline
\end{tabular}


likely be more active and more mobile than the average senior citizen in the region. It is impossible to accurately predict how this might change the responses to the survey. At worst, the survey should be representative of the opinions and attitudes of active senior citizens. Obviously, more active seniors are more indicative of those who use pedestrian facilities on a regular basis.

Table 1 contains the demographic information about the survey respondents. As can be seen, almost 85 percent of the respondents were female. This overrepresentation is most noticeable in the senior centers in Baltimore City. Approximately 18 percent of the survey responses were from African Americans, and 6 percent were from Asians. Two-thirds of the responses were from seniors who identified themselves as Caucasian. Due to the help we received from administrators, the senior centers in the City of Baltimore are very well represented in the sample. Outlying counties are not as well represented, but the number of responses from outlying areas still allows significant results to be presented.

\section{Survey Results}

Results from the survey are presented briefly in a descriptive fashion, and then the racial and gender driven results are highlighted. Attitudes toward pedestrian safety depicted in the survey responses are similar to those that researchers and professionals in the field would expect, with a few notable exceptions.

Table 2 contains the overall results of the responses of seniors to the surveys. Several results are notable, even in this overall portrayal of the results where responses were, generally, as anticipated. While over 60 percent of the seniors were from the city of Baltimore (and another $10 \%$ or so from other cities, such as Frederick), less than 50 percent claimed that they walked most often in the city. This implies that many of the seniors who live in the city either do not walk at all or go elsewhere to do their walking. Approximately 60 percent of the sample walked at least once a week. Nearly all, 96 percent, of seniors said that they thought it was important to only cross streets at a crosswalk. This is a fairly high acceptance rate for a law that does not enjoy universal acceptance among professionals or the public. However, slightly less than 75 percent of the seniors say they follow this law when they are mid-block and wish to cross the street. These numbers are not surprising and show what professionals might expect from pedestrians. 
Table 2. Responses to Survey

\begin{tabular}{|c|c|c|c|}
\hline \multicolumn{4}{|c|}{ Walking Habits of Seniors } \\
\hline \multicolumn{2}{|c|}{ P1: Where do pou walk the moit? } & \multicolumn{2}{|c|}{ n: On average, hou frecuenth do you walk on reada? } \\
\hline Rerpontie & Nericentige & Resposie & Perientage \\
\hline All & 0.765 & A few times each netk & 29.145 \\
\hline Cry & 47234 & At least once a week & $261 \%$ \\
\hline Cresubur & 0.635 & Daily & $21.00 \%$ \\
\hline Con thural & $0.36 x$ & Daily/As least oncer a werk & $0.13 \mathrm{~W}$ \\
\hline Don't know & $4.17 x$ & Dos't know & $490 \%$ \\
\hline None & a.13\% & Less than once a month & $2650 \%$ \\
\hline Bural Aveat & $1226 x$ & Less than once a werk & 10.66 \\
\hline Sobuits & $3306 x$ & $N / A$ & $0.13 x$ \\
\hline WahMart & a.134 & Never & $0.66 \%$ \\
\hline Wichin reals & a.13\% & & \\
\hline \multicolumn{4}{|c|}{ Importance of Crosswalks to Pedestrian Safety } \\
\hline \multicolumn{2}{|c|}{$\begin{array}{l}\text { P3: Do you think it's important to } \\
\text { cross the street only at crosuwallst? }\end{array}$} & \multicolumn{2}{|c|}{$\begin{array}{l}\text { P4: If you are not near a comer bet are ready to } \\
\text { cross the road, would you walk to a crosswalkf }\end{array}$} \\
\hline Response & Aercentay & Reiponue & Percentere \\
\hline Don't know & $100 \mathrm{~N}$ & Don't know & 1.145 \\
\hline No & $112 x$ & No & 23.278 \\
\hline Yes & 95768 & Yes & 73.585 \\
\hline Yec not in subuts & a.1245 & & \\
\hline \multicolumn{2}{|c|}{$\begin{array}{l}\text { PS: Do you know and underitand the } \\
\text { pedestrian lams involving croswwallat }\end{array}$} & \multicolumn{2}{|c|}{$\begin{array}{l}\text { No: What influences pour choice of } \\
\text { whether of not te we a cresswalk? }\end{array}$} \\
\hline Reipontse & Aercenber & Respoese & Percentery \\
\hline Donit know & 2928 & Aways use crosisalk & 8.435 \\
\hline No & East & Salvey of enonwalk & 41318 \\
\hline Yer & $\sin 20 \mathrm{~s}$ & Amsunt and spend of eafic & 31025 \\
\hline & & $\begin{array}{l}\text { Lights make crossaalks } \\
\text { dengerous }\end{array}$ & 3.255 \\
\hline & & $\begin{array}{l}\text { Tuming cars make corners } \\
\text { dangerout }\end{array}$ & 0.945 \\
\hline & & Ditorice to crosswalk & 1.995 \\
\hline & & Ocher answers & 7035 \\
\hline \multicolumn{4}{|c|}{ Pedestrian Salety and Children } \\
\hline \multicolumn{2}{|c|}{$\begin{array}{c}\text { 77: Do you have any children or grandchildren } \\
\text { under the age of } 187\end{array}$} & \multicolumn{2}{|c|}{ 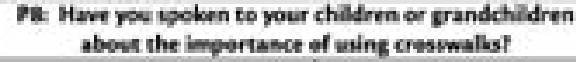 } \\
\hline Response & Percentoge & Respoese & Percentex \\
\hline No & 38578 & Don't know & $135 \%$ \\
\hline \multirow[t]{2}{*}{ Yen } & $61.43 \mathrm{~s}$ & No & 31,128 \\
\hline & & Ya & 55.318 \\
\hline \multicolumn{2}{|c|}{ nt Do you muke sure thry follow thene lawst } & \multicolumn{2}{|c|}{$\begin{array}{l}\text { P16. Are you more likely to use crosiwallos when yeu are } \\
\text { with pour childen or grandchildren }\end{array}$} \\
\hline Reiponie & Nercentage & Rriporsie & Arrientays \\
\hline Dont know & 22003 & Don'tknow & 13.454 \\
\hline No & 22368 & No & 8045 \\
\hline $\mathrm{Ya}$ & $5555 \%$ & ro & 7.225 \\
\hline
\end{tabular}


The answers to question P6 are interesting in that they give insight about why seniors might or might not use a crosswalk. Approximately 50 percent of the seniors answered in a fashion that implied they would always use a crosswalk. Other answers implied that alternatives other than the crosswalk were considered (such as a mid-block crossing). In fact, the answers to question P10 give further insight into these decisions. Almost 80 percent of seniors say they are more likely to use a crosswalk in the presence of their children or grandchildren. This means that they make a conscious decision to use the crosswalk with their children or grandchildren that they might not make if they were not present. This implies both knowledge that using crosswalks is a good habit to "pass on" and an admission that they might consider a mid-block crossing without the children or grandchildren present.

These answers highlight a fairly responsible attitude toward pedestrian safety that matches what professionals would expect from the surveyed group. Once the answers are examined demographically, there are many results that are quite insightful and, at times, surprising.

Regressions were run to determine the impact of various demographic characteristics on the responses of seniors. Table 3 contains the results of the regression for some general questions about pedestrian safety. The regressions were of the form:

$$
R_{i}=\alpha+\beta_{M} M+\beta_{U} U+\beta_{B} B+\beta_{A} A+\beta_{O} O
$$

where:

$R_{i}$ is a binary variable that is a 1 if the response is yes and 0 if the response is no

$\alpha$ represents a constant that represents the base response (see next paragraph for a full description of the interpretation of this parameter)

$\beta$ indicates a vector of parameters measuring demographic impacts on the response 
$M$ equals a binary variable that is 1 if the respondent is male and 0 otherwise

$U$ is a binary variable that is 1 if the respondent is located in Baltimore City and 0 otherwise

$B$ indicates a binary variable that is 1 if the respondent is an African American and 0 otherwise

$A$ represents a binary variable that is 1 if the respondent is Asian and 0 otherwise

$O$ is a binary variable that is 1 if the respondent is of race "Other" and 0 otherwise.

Due to the nature of the data, binary variables with little individual variance, the $\mathrm{R}$-squared values are expected to be very low. However, the F-values show that the included variables (with two exceptions) significantly impact the responses. While individual characteristics could probably be used to more accurately predict the responses of the seniors, these characteristics might not have been willingly disclosed and would not materially contribute to the principle research questions of this article.

The base is the value of $\alpha$ which represents the percentage of the base population that responded "Yes" to the question. In each case, a "Yes" response is the one more compatible with pedestrian safety or law. The base population in this case is a white female from outside of Baltimore City. The demographic results are immediately obvious. Men are significantly less likely to feel that crosswalks are imperative to safety and also less likely to go out of their way to use them. In addition, men are less likely to alter their behavior around children or grandchildren.

All but two of the models show that the included variables were significant in determining the response at the 99 percent level (F-tests). At the 90 percent level, all but one of the models show that the included variables were significant in determining the response to the question. The only question that the included variables seemed to have little impact on was "Do you know and understand the pedestrian laws involving crosswalks?" For this question, there was little deviation from the average response rate by gender or race. For this question, the only sig- 


\begin{tabular}{|c|c|c|c|c|c|c|}
\hline है & $\bar{g}$ & 2 & - & $\frac{1}{6}$ & 2 & 'f \\
\hline 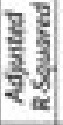 & $\overline{8}$ & 太ิ & 0 & $\hat{\xi}$ & $\frac{7}{8}$ & $\bar{q}$ \\
\hline है & 홍응 & 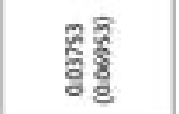 & 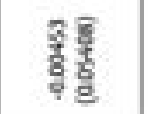 & 을 & 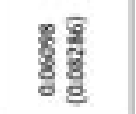 & 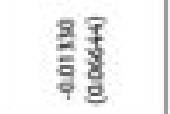 \\
\hline$\frac{\text { है }}{\text { मे }}$ & ㅇㅝㅎㅀ & 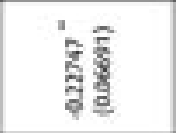 & 둥ㅎㅀ & 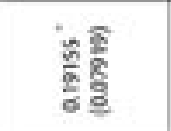 & 중 & 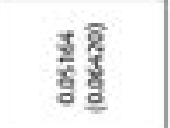 \\
\hline 产 & $\begin{array}{l}\overline{5} \\
\overline{8} \\
8 \frac{3}{8}\end{array}$ & 홍ㅎํ & 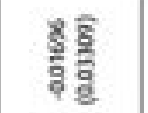 & 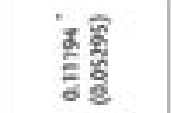 & 홍형 & 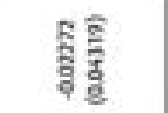 \\
\hline$\frac{5}{3}$ & 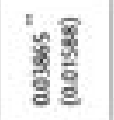 & 瑷 & ${ }^{2}$ 호용 & $\begin{array}{l}5 \overline{8} \\
\frac{2}{8}\end{array}$ & 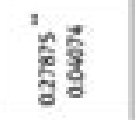 & 糙言 \\
\hline$\frac{\pi}{2}$ & $\frac{\xi}{\xi}$ & 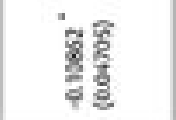 & 额 & 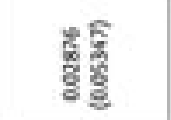 & 형영 & 危产 \\
\hline 哚 & 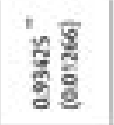 & 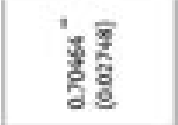 & 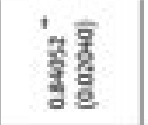 & 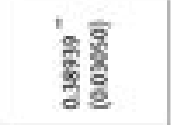 & ' & 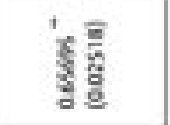 \\
\hline & 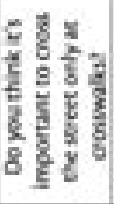 & 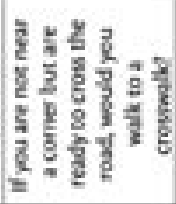 & 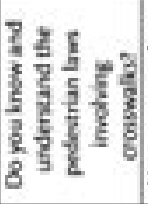 & 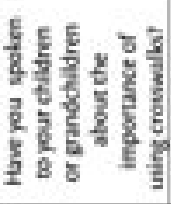 & 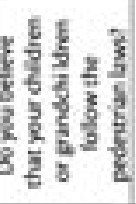 & 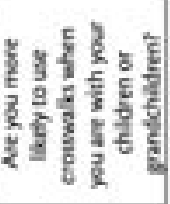 \\
\hline
\end{tabular}

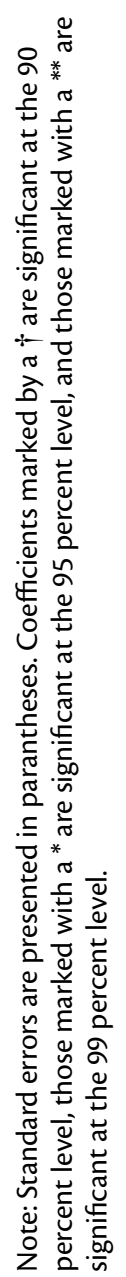


nificant coefficient is that for seniors located in urban areas. It might be possible to conclude that seniors in urban areas are more likely to understand (or claim an understanding of) pedestrian laws, but the insignificance of the model makes even that conclusion tenuous. For all other models, the conclusions about the coefficients can be made with confidence since the models themselves are statistically significant.

The responses of urban seniors were significantly more likely to be "Yes" to all questions. The increased level of interaction with motor traffic in urban environments might explain the increased safety orientation of the urban seniors. This increased consciousness of pedestrian safety matters among the urban seniors is not surprising. In addition, the more favorable pedestrian facilities found in urban areas might also contribute to this. This is consistent with Hess et al. (1999). However, the results of the breakdown of responses according to race contain some surprises.

African Americans, a group that is overrepresented in pedestrian injuries and fatalities, are consistently more likely to have given "Yes" responses to the questions. Some of these results are not significant (as most of this increase is captured by the Urban variable), but, in some of these questions, the increase in positive responses is quite significant. In both of the questions concerning the children, African Americans are more than 10 percent more likely to give a positive response. This implies a greater level of care given pedestrian safety as it concerns children or grandchildren in the African American community. More questions are examined later, and this can be viewed in a more full context.

Asians, often the safest group of pedestrians (STPP 2002), had quite remarkable figures in the analysis. Asians were about 23 percent less likely to walk to a corner to use a crosswalk than their Caucasian counterparts (27\% less likely than their African American counterparts). This result is even more surprising given the predominantly urban environment that the Asian seniors live in (most were from Baltimore City). However, they were 20 percent more likely to have spoken to their children or grandchildren about crosswalks and 26 percent more likely to believe that their children or grandchildren follow pedestrian laws. They were also 5 percent (not significant) more likely to alter their behavior around their children or grandchildren concerning using crosswalks. This number is quite significant when you realize that almost 100 percent of Asians claimed they always used crosswalks. 
The most dramatic differences across demographic groups came in evaluating the safety campaign and the most effective means of moving forward with future campaigns. Table 4 contains the results of the regressions concerning those questions. Similar to the regressions in Table 3, eight of the nine models are statistically significant at the 90 percent level and seven at the 95 percent level. With the exception of the model for those considering radio advertisements to be effective in campaigns, all other coefficients discussed come from significant models.

The "Walk Smart" campaign was a moderately publicized campaign stressing pedestrian safety. The media buy for this campaign was not very large, and it was not viewed by very many people. Results from the survey show a different story, however. It is likely that the seniors felt that any information they received about pedestrian safety from any source was part of the campaign for the purposes of these questions. Missing values are discarded for these regressions, and so the percentages reported can be misleading. For example, 53 percent of the base population recall seeing television ads concerning pedestrian safety. However, 18 percent of the survey respondents did not answer this question. This means that about 45 percent of the base population actually recalled television advertisements.

Approximately 25 percent of the base modified their behavior due to pedestrian safety campaigns. This might be a large number given the very high adherence rates claimed in the answers above. Other questions concerning message recall imply that less than half of the population recalls any messages about safety at all. Further questions, and the focus group results, revealed that many of these were referring to something other than the "Walk Smart" campaign itself.

The most telling results are those concerning the urban and minority populations. Respondents living in the City of Baltimore were about 25 percent more likely to think that the public safety campaigns had an effect on behavior. African American's were about 15 percent more likely than Caucasians to have this opinion; Asians were 30 percent more likely to have this opinion. These numbers are quite extraordinary. The positive response rate of African Americans and Asians seems to imply that they were reached by the campaigns and feel that behavior was altered. An African American from the city was almost 40 percent more likely to think the messages had a positive impact than a Caucasian from outside the city. An Asian from the city was almost 55 percent more likely to think these messages had a positive impact than the base group.

The recall questions have a somewhat vague policy implication, but the next question is very important. When asked which types of campaigns would be 


\begin{tabular}{|c|c|c|c|c|c|c|c|c|c|c|c|}
\hline L $4 \frac{3}{5}$ & $\frac{t}{t}$ & $\frac{d}{d}$ & $\frac{2}{3}$ & & in & $\underline{\Xi}$ & $\frac{1}{2}$ & & $\dot{\bar{n}}$ & $\frac{7}{3}$ & $\dot{g}$ \\
\hline 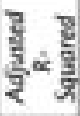 & हैं & ถิ & $\frac{8}{8}$ & & $\bar{a}$ & 8 & है & & $\bar{a}$ & है & $\frac{7}{8}$ \\
\hline 홓 & $\frac{\dot{g}}{\frac{g}{6}}$ & $\frac{\mathrm{z}}{\mathrm{z}}$ & 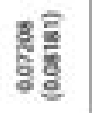 & & 둥ㅎㅀ & $\frac{3}{8}$ & $\begin{array}{l}\frac{5}{5} \\
\frac{5}{8} \\
\frac{5}{5}\end{array}$ & & $\frac{7}{8}$ & $\frac{7}{8}$ & ร \\
\hline$\frac{5}{2}$ & $\frac{\vdots}{\frac{3}{3}}$ & 害爱 & 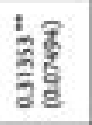 & & 둥후응 & 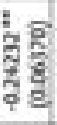 & $\frac{2}{8}$ & & $\frac{9}{\frac{8}{5}}$ & 8 & $\frac{8}{8}$ \\
\hline$\frac{\mathrm{g}}{\xi}$ & $\begin{array}{l}\frac{1}{z} \frac{g}{2} \\
\frac{g}{6} \\
\sigma\end{array}$ & 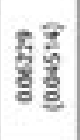 & $\frac{1}{3}$ & & 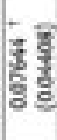 & & 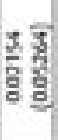 & & है & & ह5혛 \\
\hline$\frac{5}{5}$ & 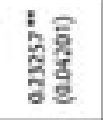 & 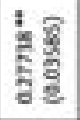 & 啇敦 & & $\begin{array}{l}\vdots \overline{3} \\
\frac{8}{8}\end{array}$ & $\frac{1}{6}$ & 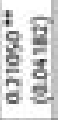 & & $\frac{2}{2}$ & & $\begin{array}{l}1 \\
\frac{8}{8} \\
\frac{8}{8} \\
\frac{8}{6}\end{array}$ \\
\hline$\frac{\text { है }}{2}$ & 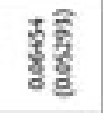 & $\frac{\vec{g}}{9}$ & 호을 & & 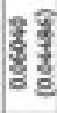 & $\frac{5}{5}$ & $\begin{array}{l}\overline{8} \\
\frac{8}{8} \\
\frac{8}{8}\end{array}$ & & 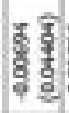 & & 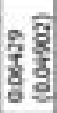 \\
\hline$\frac{\text { yे }}{\mathrm{c}}$ & $\begin{array}{l}\frac{1}{8} \\
\frac{8}{8} \\
\frac{2}{8}\end{array}$ & $\begin{array}{l}\frac{2}{3} \\
\frac{5}{3} \\
\frac{3}{8}\end{array}$ & 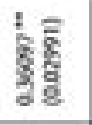 & & 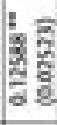 & $\begin{array}{l}6 \\
6 \\
6 \\
0\end{array}$ & $\begin{array}{l}\frac{1}{2} \\
\frac{1}{2} \\
\frac{2}{2} \\
2\end{array}$ & & $\begin{array}{l}\mathrm{t} \\
\frac{2}{2} \\
\frac{2}{2} \\
\text { d }\end{array}$ & & $\begin{array}{l}\text { to } \\
\frac{5}{2} \\
\text { 웡 }\end{array}$ \\
\hline & 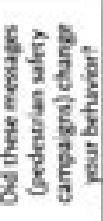 & 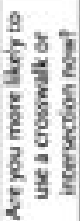 & 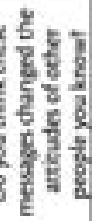 & 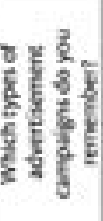 & 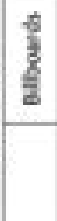 & $\frac{8}{2}$ & $\frac{8}{2}$ & 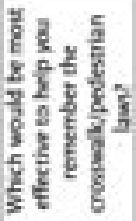 & 路 & $\frac{\delta}{\frac{\delta}{2}}$ & $\frac{8}{2}$ \\
\hline
\end{tabular}

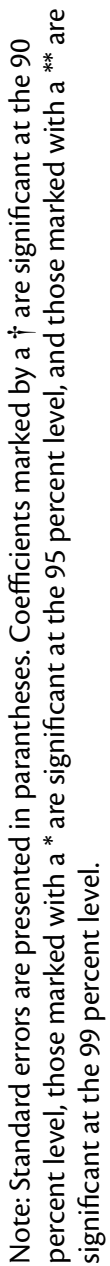


most effective in helping people remember to use crosswalks, there were large differences across demographic groups. The most important media seemed to be television. Forty percent of the base population felt that television advertisements would have the greatest impact. However, among urban African Americans, billboards ran a fairly close second, with 27 percent saying that method would be the best way to get the message across. None of the other racial groups had a signifcant deviation in terms of media of choice. However, there is a large difference in opinion concerning the use of fines.

Eighteen percent of Caucasian women outside of Baltimore supported fines as the best way to alter behavior. Men were approximately 6.5 percent more likely to feel this way. Urban white seniors were very much in favor of fines. Approximately 34 percent of urban white seniors felt that fines were the best approach. African Americans were 14 percent less likely to answer this way. This is the only question in the entire survey where African American responses were not more safety conscious or more supportive of safety campaigns. This is a striking result from a group that claims a much higher adherence to the laws. This is a strong indication of a cultural difference in feelings concerning fines and police enforcement since this group claimed that it was safer and followed the law more than their Caucasian or Asian counterparts.

\section{Focus Group Results}

The surveys were followed by focus groups conducted at six senior centers in Maryland. ${ }^{5}$ Two of these were from Baltimore City, two were from Baltimore County, and two were from outlying counties. In selecting the focus groups, we ensured that various geographic locations (namely, Baltimore City and its innerring suburbs and rural counties) were represented. Attention also was given to race in selecting these groups. While the focus groups were predominantly Caucasian in the outlying counties, one inner-city group was predominantly African American, while the other was Korean. The Baltimore County focus groups were attended by a racially-mixed group of seniors.

Our primary analytical framework for the focus groups was drawn from critical ethnography and studies of practice and discourse in public policy (Van Maanen 1988; Forester 1999; Throgmorton 1996; Watson 2002). Such a methodology relies on qualitative interpretative inquiry and seeks to understand the unique and contextual rather than make generalized propositions about the "responses." The 
focus groups were used to augment the results of the survey and to obtain other concerns that the seniors have on pedestrian and driving behavior. The seniors' concerns were not always focused on the same issues as the survey, but brought up other issues related to accessibility and safety.

The overriding focus of the survey was the use of crosswalks and the efforts of the public service campaign to encourage their use. Seniors had much to say on these topics. Concerning the public service campaigns, most seniors recalled some form of safety campaigns but none recalled the specific "Walk Smart" campaign the study was funded to examine. Most seniors felt that the reason campaigns were likely to have little effect is that they are too broad and tend to focus on issues that "everyone already knows."

The seniors had much to say concerning the impact of age and age-related handicaps on pedestrian safety. Many seniors said that vision impairment was the major difficulty they faced in getting about. They had many complaints about the accessibility of pedestrian safety tools for the vision impaired. Many echoed the concern of one senior from the Pikesville Senior Center who stated, "I am legally blind so I have trouble with curbs and steps. I have fallen so many times that I am afraid but I try [to walk] when I can." A participant from the La Plata Senior Center summed up the views expressed by many other seniors: "You will find if you walk around that there may be a ramp or crosswalk cutout for wheelchair people, but no concern has been shown for the blind and visually impaired pedestrians." This senior argued that this meant that jurisdictions were not adhering to the Federal Access Act.

Complaints concerning visual impairment and pedestrian safety issues often were linked by seniors to their being afraid, or unwilling, to risk walking in areas with vehicular traffic. The lack of friendly pedestrian facilities for the vision impaired may contribute to the lack of mobility and pedestrian activity on the part of many seniors.

Numerous comments were voiced about the placement and safety of crosswalks. Many seniors complained about the placement or usability of crosswalks. This was primarily a concern in the outlying centers. In Cumberland, one senior complained that a commonly-used crosswalk in a busy commercial district was unusable because "if you ever waited for that walk signal, it would take forever because it never works." The sheriff of Cumberland County commented, ". . . the majority of traffic here is traffic friendly not pedestrian friendly ... if you have somebody.. . with a prohibitive handicap, to get across the street you need much more than 
the time allowed by the crossing signals." He also noted that the placement of the crosswalks did not encourage their use. He explained that the distance to the crosswalks in the area immediately surrounding the senior center was such that it encouraged seniors to make a mid-block crossing "and take their life into their own hands." These comments are directly compatible with the recommendations of Langlois et al. (1997) and Carmeli (2002).

In addition to vision problems, another complaint often mentioned by seniors was the aggressiveness of motorists. This concern was not limited to rural locations but was equally shared by rural and urban seniors. A senior from the Mount Street Senior Center stated, "I don't know about the laws, but it seems to me that when you try to cross the street that the driver speeds up." Another senior pointed out that the behavior of the motorist requires the pedestrian to have to "to look out for all ways all the lights are going and get up on the side" rather than just assume a "walk" signal is safe.

The concerns of the seniors clearly show that they are afraid that motorists do not obey the laws protecting pedestrians. This lack of regard for pedestrians making crossings scares seniors to the point that many have changed their habits. Some avoid walking longer distances while others now walk at malls rather than risk vehicular traffic. This fear has further lowered the mobility of these seniors by making it difficult for them to get about on streets they share with vehicles. Interestingly, a major initiative by the Maryland State Highway Administration on just this issue was started shortly after the report was written. A massive and very public enforcement of motorist behavior around crosswalks was conducted with the police forces, highway administration, and local television stations. Citations were given to motorists who failed to slow down for "model" pedestrians and large amounts of publicity were generated.

Most of the seniors stated that they made an effort to stress pedestrian safety with grandchildren when they were young. They felt that schools contributed to this but had mixed feelings as to the effectiveness and motivation of the schools in doing so.

As for effectiveness of campaigns, most seniors felt that an aggressive campaign that was "more focused" would be better. They felt that most public service messages were virtually ignored because they were general and repeated already "known" material. They were nearly uniform, however, in supporting more aggressive enforcement of rules and regulations. They wanted drivers and pedestrians to be held accountable for their actions. A senior from La Plata stated, "Whoever is 
wrong should get a ticket." This opinion held equally for pedestrians and motorists. A senior from Cockeysville said, "I think you wouldn't do it more than once if you got a ticket for illegally crossing."

\section{Conclusions and Policy Implications}

The study shows that seniors consider pedestrian safety an important issue and that they are concerned about their safety when walking on roads. Both the survey responses and the focus group comments underscore this concern. The extra care shown in the presence of their children or grandchildren further highlights the concern given this subject. Yet, this is the group of people most vulnerable to accidents (Winter 1984; Harrell 1996; Carmeli et. al. 2000). This necessitates the need to design cities that are safe for the elderly.

The study also found several key results that are important for understanding the attitudes concerning pedestrian safety. First, attitudes differed across demographic, racial, gender, and geographic groups. Urban seniors were considerably more likely to claim that they act safely than those living in nonurban areas. There is an interesting dichotomy between the groups most at risk of pedestrian accidents and those who believe that they are acting safely. National and regional data both suggest that minorities are disproportionately represented in the pedestrian accident figures. However, minority respondents to the survey felt that they were acting properly more often than their Caucasian counterparts.

It is clear that pedestrian activity differs between urban and nonurban environments. The density of traffic, both pedestrian and automobile, creates a situation in which there are numerous interactions between pedestrians and automobiles in an urban environment. In less urban environments, the number of interactions is lower, but automobiles travel at higher speeds. Urban pedestrians are likely to be more aware of traffic yet they are constantly exposed to potentially dangerous interactions. In less-dense suburban and exurban environments, pedestrian facilities are often more sparse and less well designed.

The results of the study show that urban seniors claim a higher degree of pedestrian safety awareness and conformity with safe practices. This is compatible with the enhanced awareness that comes from repeated interactions and the infrastructure being more amenable to safe practices. Surprisingly, there were strong differences along racial lines, after controlling for geographic location, in the responses to the survey. 
Differences along racial lines were striking in their strength and their consistency. African Americans were more likely to give the positive safety response to nearly every question. The magnitude of this difference was also quite stable. For most of these questions, the positive response was approximately 10 percent more likely from an African American respondent. Asian respondents were even more strongly positive than African American responses. This provides a policy dilemma for transportation agencies striving to lower pedestrian accident rates. The very groups that are disproportionately represented in the accident data feel that they are acting safely already. This could make the task of informing and altering behavior more difficult. One of the basic principals of environmental justice is to avoid, minimize, or mitigate disproportionately high and adverse human health and environmental effects on minority populations. Clearly, our study suggests that more attention needs to be paid to the safety of minorities if we are to minimize or mitigate relatively higher and adverse affects of fatal pedestrian accidents on this segment of the population. Agencies charged with safety issues should be aware of this dilemma, and future studies should focus on discovering the best means to overcome it.

The differences across racial lines continued into message recall and suggested means of conveying the message. Urban seniors and African Americans were much more likely to have recalled seeing billboard advertisements. In addition, they were more likely to feel that billboards would be an effective means of conveying the message. One interesting deviation from this trend is that urban seniors were much more likely to feel that tickets were a good means of promoting good pedestrian behavior. However, African Americans were much less likely to agree with this method. This is a strong indication of a cultural difference in feelings concerning fines and police enforcement since this group claimed that it was safer and followed the law more than their Caucasian counterparts.

The study found a large difference in attitudes toward pedestrian safety and public safety campaigns across racial lines. This highlights the importance of considering the target audience for any public safety campaign. Differences in attitudes and responses imply that different tactics may be necessary to get the same message across to different audiences. The fact that the differences in responses were racial and not geographic strongly argues for more study concerning the attitudes of pedestrians toward safety and public safety campaigns. This, in combination with the results of Russell et al. (2001), shows that there may be significant differences 
in the behavior and attitude of pedestrians along racial lines. Taking this into consideration is critical to achieving stated policy objectives by any planning agency.

In addition, different target groups have different preferred means of receiving information. Urban, and particularly African American, seniors are more likely to think that billboards are the most appropriate means of publicizing safety issues. Nonurban, and particularly Caucasian, seniors are more likely to believe that radio and television advertisements are more appropriate. In contrast to the survey responses, focus group discussions implied that seniors believe that stricter rules and enforcement may be better than public safety campaigns. This suggests that public agencies, transportation and otherwise, have to be more proactive about considering the cultural aspects of campaigns. These include appropriate themes, appeals, and media vehicles.

Although the nature of the focus groups precludes generalized conclusions, the findings imply that the goals ISTEA and TEA-21 may not be fully met as of today. The elderly were annoyed or are unhappy with aggressiveness of the motorists, felt insecure about bicyclists, and were concerned about pedestrian "unfriendliness" of streets and pedestrian crossings.

The trend to include stakeholders' views in policy has been embraced in some parts of policy-making and is lagging in others. The use of pedestrian facilities is an important part of any public transportation planning process. The views expressed by the seniors in this study show that there is still a considerable distance to go in order to fully incorporate the needs of all groups in transportation policy. If the goal of planning is to create livable communities where all stakeholders are represented in the process, pedestrian safety issues need to be addressed and the concerns of various demographic groups considered.

\section{Endnotes}

1 The concept of sustainability emerged in the 1970s, but a large volume of literature on sustainable development began to emerge from the late 1980s, especially in the international context (See, for example, Beatley 1995; Mitlin 1992).

${ }^{2}$ Of course, there are other concerns for sustainable and livable cities such as environmental justice, self-reliance, reduced waste and pollution, reuse of and recycling of materials, and development of a locally self-reliant economy (see Wheeler 2000; Haughton 1999). 
${ }^{3}$ See Bullard and Johnson 1997; Forkenbrock and Schweitzer 1999; Sanchez 1999; and Khisty 2000. This act aims to enhance the mobility of low-income populations to job sites. In addition to job access, other related issues, such as fairness of transit service pricing and quality of service provision, have also been of recent concern.

${ }^{4}$ These and other acts, and their stipulations on equity and citizen participation, are discussed below.

${ }^{5}$ These were Alleganey County Senior Center, Cumberland; Richard R. Clark Senior Center, LaPlata; Greenmount Senior Center, Baltimore; Mount Street Senior Center, Baltimore; Cockeysville Senior Center, Cockeysville; and Pikesville Senior Center, Pikesville.

\section{Acknowledgments}

The authors would like to thank the Maryland State Highway Administration and the National Transportation Center at Morgan State for funding the original study. Kinjal Parikh, Sachin Parekh, Julius Maura, Carla Bauer, and Brett Ripkin provided valuable research assistance on the project. We would also like to thank the referees and the editors of the journal for their constructive criticisms, and senior centers and administrative personnel that helped distribute and complete the surveys and accommodate the focus groups. 


\section{References}

Beatley, Timothy. 1995. Planning and sustainability: The elements of a new (improved) paradigm. Journal of Planning Literature 9, 4: 383-395.

Bullard, R. D., and G. S. Johnson, eds. 1997. Just transportation: Dismantling race and class barriers to mobility. Gabriola Island, BC: New Society Publishers.

Campos-Outcalt, D., C. Bay, A. Dellapena, and M. K. Cota. 2003. Motor vehicle crash fatalities by race/ethnicity in Arizona, 1990-96. Injury Prevention 9: 251-256.

Carmeli, E., R. Coleman, H. L. Omar, and D. Brown-Cross. 2000. Do we allow elderly pedestrians sufficient time to cross the street in safety? Journal of Aging and Physical Activity 8: 51-58.

Duany, Andres, Elizabeth Plater-Zyberk, and Jeff Speck. 2000. Suburban nation: The rise of sprawl and decline of the American dream. New York: North Point Press.

Frey, Hildebrand. 1999. Designing the city: Toward a sustainable urban form. New York: Routledge.

Forester, J. 1999. The deliberate practitioner: Encouraging participatory planning processes. Cambridge, MA: MIT Press.

Forkenbrock, D. J., and L. A. Schweitzer. 1999. Environmental justice in transportation planning. Journal of the American Planning Association 65, 1: 96-111.

Gårder, P. E. 2004. The impact of speed and other variables on pedestrian safety in Maine. Accident Analysis and Prevention 36: 533-542.

Harrell, W. A..1996. The safety of older pedestrians at signal-controlled crossings. International Journal of Aging and Human Development 42, 1:65-79.

Haughton, Graham. 1999. Environmental justice and the sustainable city. Journal of Planning Education and Research 18, 3: 233-243.

Hess, P. M., A. V. Moudon, M. C. Snyder, and K. Stanilov. 1999. Site design and pedestrian travel. Transportation Research Record 1674: 9-19.

Hess, P. M. A. V. Moudon, and J. M. Matlick. 2004. Pedestrian safety and transit corridors. Journal of Public Transportation 7, 2: 73-93. 
Horan, Thomas. A., and Daniel R. Jordan. 1998. Integrating transportation and telecommunications planning in Santa Monica. Journal of Urban Technology 5, 2: 1-20.

Kay, J. H. 1997. Asphalt nation: How the automobile took over the nation and how we can take it back. New York: Random House.

Khisty, C. J. 2000. Citizen involvement in the transportation planning process: What is and what ought to be? Journal of Advanced Transportation 34, 1: $125-142$.

Langlois, J. A., P. M. Keyl, J. M. Guralnik, D. J. Foley, R. A. Marotolli, and R. B. Wallace. 1997. Characteristics of older pedestrians who have difficulty crossing the street. American Journal of Public Health 87, 3: 393-397.

Mendelsohn, H. 1973. Some reasons why information campaigns succeed. Public Opinion Quarterly 37, 1: 50-61.

Mitlin, Diana. 1992. Sustainable development: A guide to the literature. Environment and Urbanization 4, 1:111-124.

Passwell, R. E. 2001. Intelligent transportation systems: Creating operational, institutional, and labor force changes in the United States. Journal of Urban Technology 8, 2: 61-73.

Reed, Randal, and Siddhartha Sen. 2004. Evaluation of pedestrian safety campaign. Maryland State Highway Administration Report SP007B4C.

Russell, J. C., D. O. Wilson, and J. F. Jenkins. 2001. Informational properties of jaywalking models as determinants of imitated jaywalking: An extension to model sex, race and number. Sociometry 39, 3: 270-273.

Sanchez, T. W. 1999. The connection between public transit and employment: The cases of Portland and Atlanta. Journal of the American Planning Association 65, 3: 284-296.

Surface Transportation Policy Project. 2002. Mean streets 2002: Pedestrian safety, health and federal transportation spending. www.transact.org.

Throgmorton, J. 1996. Planning as persuasive storytelling: The rhetorical construction of Chicago's electrical future. Chicago: University of Chicago Press. 
Tyrrell, R. A. , C. W. Patton, and J. O. Brooks. 2004. Educational interventions successfully reduce pedestrians' overestimates of their own night time visibility. Human Factors 46, 1: 170-182.

Van Maanen. J. 1988. Tales of the field: On writing ethnography. Chicago: University of Chicago Press.

Watson, Vanessa. 2002. Do we learn from planning practice? The contribution of the practice movement to planning theory. Journal of Planning Education and Research 22, 2: 178-187.

Wheeler, Stephen M. 2000. Planning for metropolitan sustainability. Journal of Planning Education and Research 20, 2: 133-145.

Winter, D. J.1984. Needs and problems of older drivers and pedestrians: An exploratory study with teaching learning implications. Educational Gerontology 10: 135-146.

\section{About the Authors}

RANDAL REED (rreed@eng.morgan.edu) is an assistant professor at the Institute for Transportation at Morgan State University. He has a B.A. and M.A. in economics, and a Ph.D. in economics from Northwestern University. His research focuses on the impacts of congestion and transportation infrastructure on the local population and the users of the facilities.

SIDdhARTHA SEN (ssen@morgan.edu) is a professor in the Graduate Program in City and Regional Planning at Morgan State University. He has a B.Arch., M.Arch., and an M.CP. and received a Ph.D. in regional planning from the University of Illinois at Urbana-Champaign. His research interests are in equity and transportation planning. 